\title{
Synthesis of boron nitride nanotubes from unprocessed colemanite
}

\author{
Saban Kalay, Zehra Yilmaz and Mustafa Çulha*
}

\author{
Full Research Paper \\ Address: \\ Department of Genetics and Bioengineering, Yeditepe University, \\ Atasehir, 34755 Istanbul, Turkey \\ Email: \\ Mustafa Çulha* - mculha@yeditepe.edu.tr \\ * Corresponding author \\ Keywords: \\ boron nitride nanotube; chemical vapor deposition; colemanite; \\ synthesis
}

\author{
Beilstein J. Nanotechnol. 2013, 4, 843-851. \\ doi:10.3762/bjnano.4.95 \\ Received: 27 August 2013 \\ Accepted: 07 November 2013 \\ Published: 04 December 2013 \\ Associate Editor: J. J. Schneider \\ (C) 2013 Kalay et al; licensee Beilstein-Institut. \\ License and terms: see end of document.
}

\begin{abstract}
Colemanite $\left(\mathrm{Ca}_{2} \mathrm{~B}_{6} \mathrm{O}_{11} \cdot 5 \mathrm{H}_{2} \mathrm{O}\right)$ is a natural and new precursor material for the synthesis of boron nitride nanotubes (BNNTs). BNNTs have been synthesized from unprocessed colemanite for the first time. The reaction parameters such as time, catalyst type, catalyst amount and temperature were optimized. It was found that the BNNT formation follows the base growth mechanism, which was initiated with a complex of boron nitride $(\mathrm{BN})$ and iron atoms. The obtained BNNTs were characterized by using SEM, TEM, and spectroscopic techniques such as UV-vis, Raman, FTIR and XRD. The BNNTs were randomly oriented and multi-walled with an outer diameter of 10-30 $\mathrm{nm}$ and a wall thickness of $5 \mathrm{~nm}$. This novel BNNT synthesis method can be used to obtain high yield, low cost and pure BNNTs.
\end{abstract}

\section{Introduction}

Colemanite $\left(\mathrm{Ca}_{2} \mathrm{~B}_{6} \mathrm{O}_{11} \cdot 5 \mathrm{H}_{2} \mathrm{O}\right)$ is one of the most important compounds of more than 200 different boron ores. All boron ores include boron oxide $\left(\mathrm{B}_{2} \mathrm{O}_{3}\right)$ at varying percentages in their chemical composition [1]. The colemanite contains $50.8 \% \mathrm{~B}_{2} \mathrm{O}_{3}$ and is used in many applications including the fibre glass industry, the ceramic industry, the steel industry, boron alloys, and metallurgy. Another use of colemanite is the synthesis of boric acid $\left(\mathrm{H}_{3} \mathrm{BO}_{3}\right)$ [2]. $\mathrm{B}_{2} \mathrm{O}_{3}$ and $\mathrm{H}_{3} \mathrm{BO}_{3}$ are also used to synthesize boron nitride nanotubes (BNNT)s [3,4].

BNNTs, structural analogoues of carbon nanotube (CNT)s, have superior properties than CNTs due to their robust struc- ture which resists high temperatures and harsh chemical conditions. They also have a high hydrogen storage capacity due to the ionic nature of the B-N bond [5]. In contrast to CNTs, the BNNTs have a constant and wide band-gap of $5.5 \mathrm{eV}$. Therefore, they are electrical isolators independent from their size or chirality. In recent studies, it has been indicated that the hydrogen storage capacity of BNNTs is two times greater than that of CNTs [6]. It has been theoretically demonstrated that BNNTs can capture ions selectively creating superhydrophobic surfaces $[7,8]$. Since hexagonal boron nitrides (h-BNs) have a $\mathrm{sp}^{2}$ hybridization, the BNNTs can interact with polymers possessing aromatic rings via $\pi-\pi$ interaction. Therefore, the 
BNNT-polymer composites can be prepared from polymeric structures containing aromatic moities to enhance their dispersibility in organic solvents $[9,10]$. DNA and proteins such as ferritin are used to disperse BNNTs in aqueous solutions for biological applications [11]. The BNNTs are also used to develop nanoscale microfluodic devices [12]. Although there are different conflicting reports about the toxicity of BNNTs, it has been shown in a recent study with human embryonic kidney cells (HEK293), lung epithelial cells (A549), fibroblast cells (3T3-L1), and alveolar macrophages (RAW 264.7) that BNNTs are more toxic than CNTs [13].

The first BNNTs were synthesized by Chopra et al. with the arc-discharge method [14]. Later, the use of chemical vapor deposition (CVD), laser ablation, ball milling, a templateassisted process, and displacement reactions were reported for the synthesis [15-19]. In the template-assisted synthesis, a commonly used method, the BNNTs are synthesized by using CNTs or an aluminum filter as templates $[15,17]$. The CNTs interact with $\mathrm{B}_{2} \mathrm{O}_{3}$ and $\mathrm{NH}_{3}$ gas to replace $\mathrm{C}$ atoms with $\mathrm{B}$ and $\mathrm{N}$ atoms to form tubes which contain $\mathrm{C}, \mathrm{B}$ and N. Finally, an oxidation process is applied to remove the remaining $\mathrm{C}$ atoms from the tube structure [18]. However, removal of $\mathrm{C}$ atoms from the structure is not easy and the obtained product is mostly carbon doped BNNTs. CVD is another commonly used method to synthesize BNNTs [19-22]. The CVD method can be used with or without ball milling technique $[19,20]$. For instance, Yu et al. first milled amorphous boron with $\mathrm{NH}_{3}$, then completed the synthesis by using the CVD method at $1200{ }^{\circ} \mathrm{C}$ for 8 hours without the utilization of a catalyst. Zhong et al. obtained BNNTs by using ammonium boron powders and ferrocene with the CVD technique under a $\mathrm{N}_{2}$ atmosphere at $1450^{\circ} \mathrm{C}$ for one hour. Okan et al. reported a method based on CVD to produce BNNTs in the $\mathrm{Fe}_{2} \mathrm{O}_{3} / \mathrm{MCM}-41$ complex-catalyst system from boron powder as a starting material at $600{ }^{\circ} \mathrm{C}$ for one hour. In another study, Singhal et al. obtained BNNTs from the mixture of $\mathrm{KBH}_{4} / \mathrm{NH}_{4} \mathrm{Cl}$ between $800{ }^{\circ} \mathrm{C}$ and $1000{ }^{\circ} \mathrm{C}$ in the presence of $\mathrm{N}_{2}$ gas with the CVD method. Wang et al. synthesized BNNTs from the obtained initial product by using $\mathrm{B}_{2} \mathrm{O}_{3}, \mathrm{Mg}$, and $\mathrm{CaB}_{6}$ at $1150{ }^{\circ} \mathrm{C}$ for 6 hours with the $\mathrm{CVD}$ technique. In addition, it was shown that in the CVD method, temperature could be decreased to $600{ }^{\circ} \mathrm{C}$ with the use of a laser-ablation technique [22]. As can be concluded from these studies, CVD is a commonly used technique to synthesize BNNTs.

The BNNT synthesis and growth mechanism depend on the reaction parameters such as substrate, catalyst and temperature but the mechanism has not been elucidated yet. According to the nucleation theory, the formation of a core depends on surface energy, supersaturation, vapor pressure, temperature and binding energy $[23,24]$. To synthesize unique, high yield and large scale BNNTs, the synthesis mechanism has to be clearly understood. At the moment, two synthesis mechanisms have been suggested: the base growth mechanism and the tip growth mechanisms $[19,25,26]$. The linear BNNTs are obtained with the base growth mechanism [19]. In the tip growth mechanism, the catalyst is located on the tip of growing BNNTs [26]. Thus, the BNNTs are generally formed in bamboo-like structures. However, the mechanism of the synthesis BNNTs with the CVD method has not been completely clarified yet.

To the best of our knowledge, unprocessed colemanite has not previously been used as a precursor for the BNNT synthesis. In this study, we demonstrate the synthesis of BNNTs from unprocessed colemanite. The reaction parameters such as the amount of colemanite, the type and amount of catalyst, the reaction temperature and duration were studied and optimized. Finally, the formation mechanism of BNNTs was elucidated. The synthesized BNNTs were characterized with several imaging and spectroscopic techniques including SEM, TEM, HRTEM, FTIR, Raman, UV-vis. The impurity of the BNNTs was verified with ICP-MS and XRD. It was found that the metallic impurities could be removed from crude BNNTs by washing in a hot $\mathrm{HCl}$ solution. With this method, randomly oriented BNNTs with 10-30 nm size ranges in high yields can be easily synthesized directly from colemanite.

\section{Results and Discussion BNNT synthesis}

In recent studies, particularly amorphous boron has been preferred as the precursor boron compound to synthesize highyield BNNTs $[5,27,28]$. Colemanite as the most important of boron ores can be used for the synthesis of BNNTs since it contains $\mathrm{B}_{2} \mathrm{O}_{3}$ in its structure. In this study, the influence of temperature, type of catalyst, and reaction time on the BNNT yield and the structure were investigated. The most important factor in BNNT synthesis is the proper selection of the catalyst. For this purpose $\mathrm{Fe}, \mathrm{Al}$ or $\mathrm{Mg}$ are widely used in the synthesis of BNNT $[3,6]$. In this study, four types of catalysts, namely $\mathrm{ZnO}, \mathrm{Al}_{2} \mathrm{O}_{3}, \mathrm{Fe}_{3} \mathrm{O}_{4}$, and $\mathrm{Fe}_{2} \mathrm{O}_{3}$, were investigated for their performances. Figure 1a-d shows 4 SEM images of reaction mixtures under the same experimental conditions but each of which carried out with a different catalyst. When there is no catalyst, only a few BNNTs are observed in the reaction mixture as seen in Figure 1a (indicated with an arrow). This may be due to the catalysis of $\mathrm{Mg}$ or other metal oxide impurities in the colemanite sample. The BNNTs were not formed when $\mathrm{ZnO}$ (data not shown) or $\mathrm{Al}_{2} \mathrm{O}_{3}$ (Figure $1 \mathrm{~b}$ ) was used. For the initiation of the synthesis reaction the catalyst in the reaction mixture must be as close as possible to the reaction mixture surface to interact with $\mathrm{NH}_{3}$ gas. Since these metal oxides stay buried under the colemanite due to the density difference, they do not 

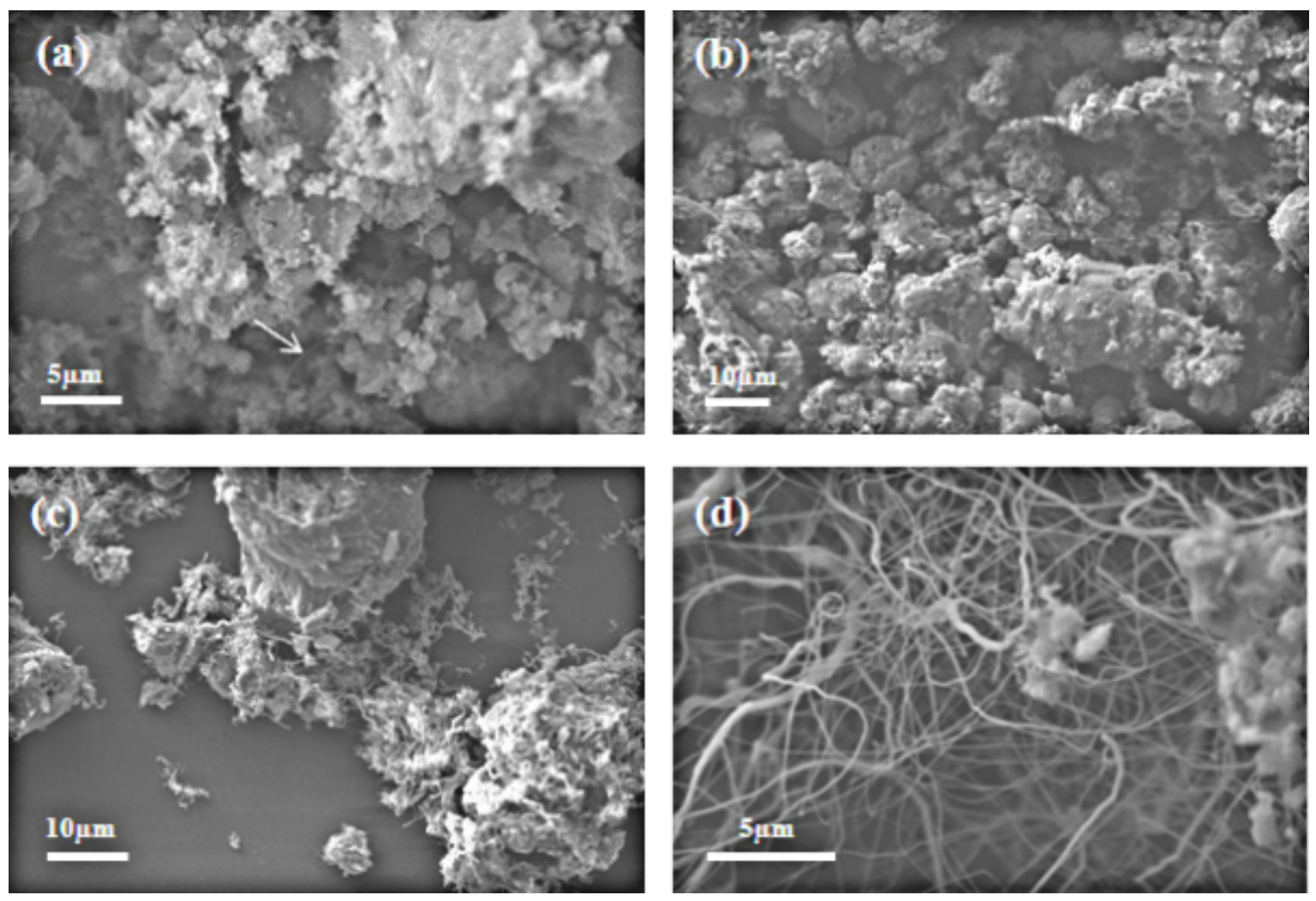

Figure 1: SEM images showing the influence of catalyst on synthesis of $\mathrm{BNNTs}$. (a) No catalyst, (b) $\mathrm{Al}_{2} \mathrm{O}_{3},(\mathrm{c}) \mathrm{Fe}_{3} \mathrm{O}_{4}$, and (d) $\mathrm{Fe}_{2} \mathrm{O}_{3}$.

effectively interact with $\mathrm{NH}_{3}$ gas. Therefore, no BNNT formation was observed. However, when iron oxides were used as catalysts, the formation of BNNTs was dramatically improved. The BNNTs synthesized with the use of $\mathrm{Fe}_{3} \mathrm{O}_{4}$ (Figure 1c) or $\mathrm{Fe}_{2} \mathrm{O}_{3}$ (Figure 1d) are clearly seen in the reaction mixtures on the SEM images. When $\mathrm{Fe}_{3} \mathrm{O}_{4}$ was used, the diameter of the BNNTs was dramatically increased and zigzag structures with shorter length were observed as seen in Figure 1c. When $\mathrm{Fe}_{2} \mathrm{O}_{3}$ was used, a lot of BNNTs with linear but smaller lengths was obtained (Figure 1d). This clearly indicates that the mechanisms of the two different iron oxide catalysts, $\mathrm{Fe}_{3} \mathrm{O}_{4}$ or $\mathrm{Fe}_{2} \mathrm{O}_{3}$, are rather different. The SEM images showed that the BNNTs were obtained in high yield from colemanite as the starting compound with CVD technique in the presence of $\mathrm{Fe}_{2} \mathrm{O}_{3}$ and $\mathrm{NH}_{3}$ gas at $1280{ }^{\circ} \mathrm{C}$.

Only the use of $\mathrm{Fe}_{2} \mathrm{O}_{3}$ resulted in high yield BNNTs, so that the reaction conditions in the presence of this catalyst were further optimized. It was found that the optimum temperature for the BNNT synthesis was $1280{ }^{\circ} \mathrm{C}$. Next, the reaction time on the yield and the size composition of BNNTs were investigated. The reaction was set to $30,60,120$ and $150 \mathrm{~min}$. Then, the obtained BNNTs were analyzed by SEM (Figure $2 \mathrm{a}-\mathrm{c}$ ). No BNNTs synthesis was observed at $30 \mathrm{~min}$. As the reaction time increased from 30 to 120 , the formation of BNNTs was more complete. The BNNTs formed at 60 min were shorter. When the time was increased to $120 \mathrm{~min}$, a high yield of the BNNTs was observed. Further increase of the time to $150 \mathrm{~min}$ did not alter the yield. It was found that when the reaction time was increased, the length of the formed BNNTs was increased. A mixture of nanotubes and nanowires, whose lengths were around $20 \mu \mathrm{m}$, were obtained at $120 \mathrm{~min}$. We concluded that the ideal reaction time for high yield BNNT formation was $120 \mathrm{~min}$.

Next, the influence of the amount of $\mathrm{Fe}_{2} \mathrm{O}_{3}$ on the BNNT formation was investigated. Predetermined 32:1, 16:1, 12:1 and $8: 1$ colemanite/catalyst $(\mathrm{w} / \mathrm{w})$ ratios were tested. A few BNNTs formed when the ratio was 32:1 (Figure 2d). Some BN structures were clustered when the ratio was 16:1 (data not shown). We obtained a rather high yield of BNNTs with a 12:1 ratio of the catalyst (Figure 2c). Finally, an 8:1 ratio of the catalyst caused the formation of BNNTs with a large diameter, which were thick and had a zigzag structure (Figure 2e). The SEM images presented in Figure 2 show the reaction mixtures obtained with a colemanite/catalyst ratio of 12:1 at 30, 60 and $120 \mathrm{~min}$ ( $\mathrm{a}, \mathrm{b}$ and c, respectively), and colemanite/catalyst ratios of 12:1, 32:1 and 8:1 at $120 \mathrm{~min}$ (c, d, and e respectively). 

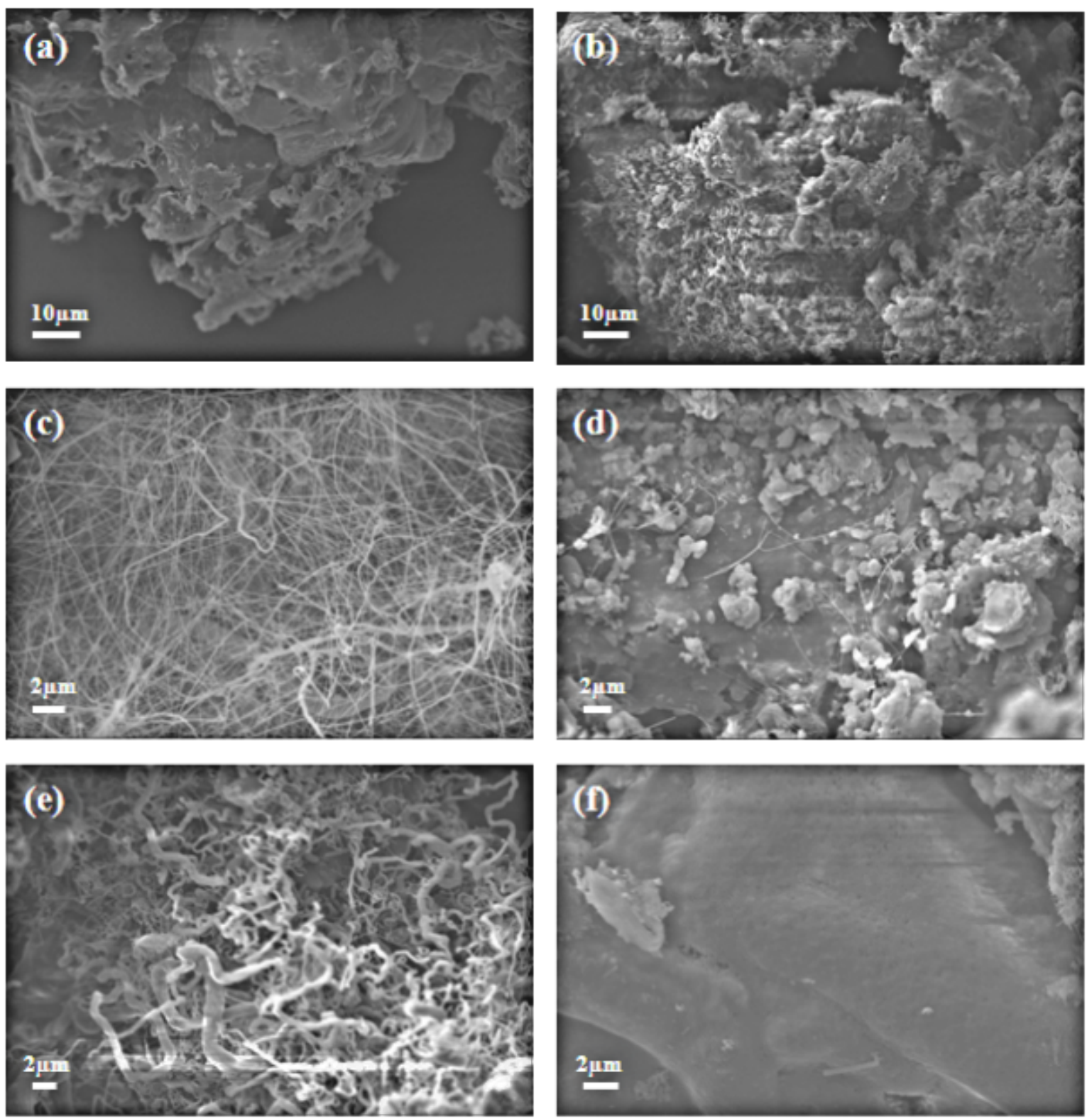

Figure 2: SEM images of the reaction mixtures with increasing reaction times $(a-c)$ and colemanite/catalyst ratios $(w / w)(d-f)$. With a ratio of $12: 1$ at (a) $30 \mathrm{~min}$, and (b) $60 \mathrm{~min}$. At 120 min with a ratio of (c) 12:1 (d) 32:1 and (e) 8:1. (f) Boat surface after removal of BNNTs, at 120 min and with a ratio of $12: 1$.

Our observations suggest that the BNNT synthesis consists of the clustered structures composed of boron nitride (BN) and iron atoms. The initial BN-Fe complex shown with arrows in Figure $3 \mathrm{a}$ has onion-shaped round structures at the bottom. The base growth BNNT formation mechanism proposes that the BNNTs are formed on the surface of the catalysts and the BNNTs grow perpendicular to the catalyst surface as soon as the BN-Fe initial complex is formed [25]. Based on our observations we propose a similar growth mechanism for the formation of BNNTs from colemanite. Another important point in the synthesis of BNNTs is the reaction termination temperature (i.e., the removal of the reaction boat from the tubular furnace). Since a high yield of BNNTs was obtained, the reaction was terminated at $450-550{ }^{\circ} \mathrm{C}$.

The reason for not observing a high yield of BNNTs at temperatures lower than $450{ }^{\circ} \mathrm{C}$ may be due to the decomposition temperature of $\mathrm{NH}_{3}$, which is $450{ }^{\circ} \mathrm{C}$. The decomposed $\mathrm{NH}_{3}$ has an important role in the synthesis of BNNT. It was observed that while the BNNTs were formed on top of the alumina boat, BNNT was not formed at the bottom of the reaction mixture (Figure 2f). 

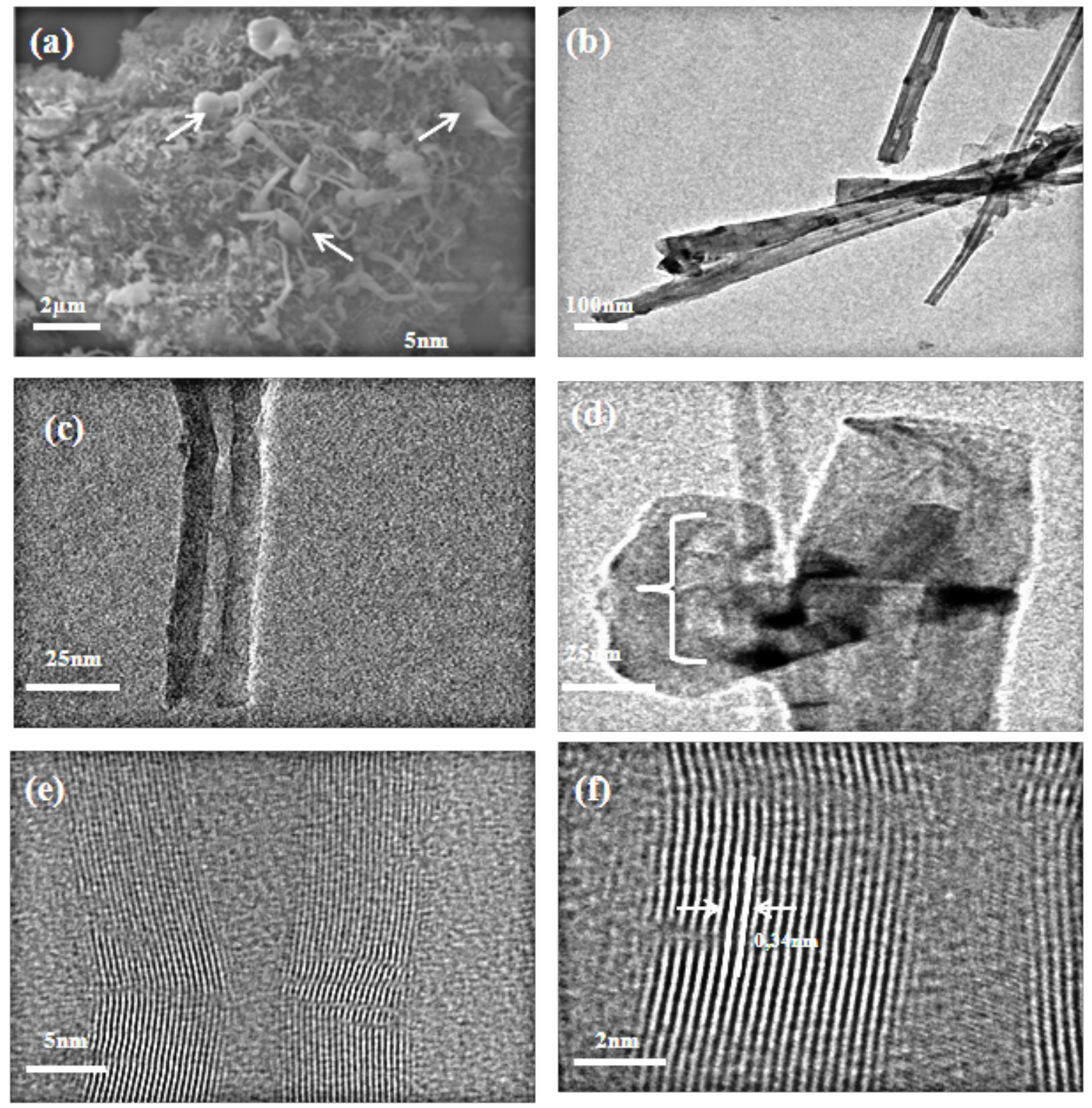

Figure 3: TEM and HRTEM images of BNNTs. (a) SEM image of initial compounds of BNNTs synthesized according to the base growth mechanism (White arrows show initially formed Fe-BN complexes), (b) and (c) TEM image of an open-ended BNNT, (d) TEM image of BNNT with bamboo-like structure, (e) and (f) High resolution TEM images of BNNTs.

\section{TEM and HRTEM analysis}

The structure of BNNTs was further analyzed with TEM (JEOL-2100). As seen in the TEM images in Figure 3, the BNNTs are multi-walled and have an outer diameter ranging from $10 \mathrm{~nm}$ to $30 \mathrm{~nm}$. The $\mathrm{Fe}_{2} \mathrm{O}_{3}$ catalyst was not observed on the tip of BNNTs and they were open-ended (Figure $3 \mathrm{~b}$ and c). The wall thickness of these BNNTs ranges from $5 \mathrm{~nm}$ to $6 \mathrm{~nm}$ (Figure 3e and $\mathrm{f}$ ). The HRTEM image of the synthesized BNNT showed that the distance between the walls was $0.34 \mathrm{~nm}$. We propose that the BNNTs are synthesized according to the base growth mechanism. In this mechanism, metallic Fe in a certain size forms from the $\mathrm{Fe}_{2} \mathrm{O}_{3}$ catalyst. This initial step of metallic catalyst formation is the most important step in the synthesis of BNNTs. When a higher amount of $\mathrm{Fe}_{2} \mathrm{O}_{3}$ is used at the beginning of the synthesis, the formed metallic Fe can form aggregates. When a lower amount of $\mathrm{Fe}_{2} \mathrm{O}_{3}$ is used, a low yield of the BNNT synthesis is observed. This suggests that a critical colemanite/catalyst ratio plays a key role. The second step is the formation of the BN initial complex on the surface of already formed Fe metallic catalyst. This initial complex including metallic Fe catalyst is shown with arrows in Figure 3a. Upon formation of the initial complex, radically decomposed $\mathrm{NH}_{3}$ at 
$1280{ }^{\circ} \mathrm{C}$ and boron are involved with the growth on the metallic Fe surface. When $\mathrm{B}$ and $\mathrm{N}$ are super-saturated, the $\mathrm{BN}$ core begins to grow on the surface of the metallic Fe surface. The open-ended BNNTs get longer with the support of continuously added $\mathrm{B}$ and $\mathrm{N}$ on the surface of the catalyst, and then the BNNTs formation was completed (Figure 3b).

In most of the synthesis where amorphous boron is used as a substrate, it is possible to observe bamboo-like tubular structures, and we detected similar structures in our study [29] (Figure 3d). The formation of metallic Fe clusters with certain sizes also suggests that the BNNT synthesis starts on the metallic Fe cluster surfaces.

Reaction stoichiometry and temperature may result in yielding BNNTs with different morphologies such as open-ended or closed-ended, straight-oriented or randomly-oriented and flower-like with the CVD method. It was reported that the flower-like morphology is only obtainable at $1400{ }^{\circ} \mathrm{C}$ [25]. In our study, a few flower-like BNNTs were also observed at $1280{ }^{\circ} \mathrm{C}$.

\section{Purification of BNNTs, ICP-MS and XRD results}

The purification of the synthesized BNNTs was evaluated with ICP-MS. The results showed that the colemanite contains $129.30 \pm 1.70 \mathrm{ppm} \mathrm{B}, 9.10 \pm 0.10 \mathrm{ppm} \mathrm{Mg}, 207.60 \pm 4.20 \mathrm{ppm}$ $\mathrm{Ca}, 5.62 \pm 0.08 \mathrm{ppm} \mathrm{Sr}$ (see Table 1). In this BNNT crude product synthesized by using colemanite, $40.04 \pm 1.66$ ppm Fe was found in addition to $\mathrm{Ca}, \mathrm{B}$ and $\mathrm{Mg}$. The crude product was incubated and stirred in $4 \mathrm{M} \mathrm{HCl}$ for four hours at room temperature to remove $\mathrm{Fe}$ impurities. Washing with $4 \mathrm{M} \mathrm{HCl}$ reduced the $\mathrm{Fe}$ and $\mathrm{Ca}$ content approximately to a rate of $2 / 3$. When the same washing was applied at $90{ }^{\circ} \mathrm{C}, \mathrm{Fe}, \mathrm{Ca}$ and other impurities were almost completely removed. Note that washing with hot $4 \mathrm{M} \mathrm{HCl}$ was very important to obtain pure BNNTs. After washing with $\mathrm{HCl}$ solution, pure BNNTs were obtained by washing with $1 \mathrm{M} \mathrm{HNO}_{3}$ for six hours. The only observed impurity in the final purified BNNT sample was $\mathrm{Ca}$ in an amount of $5.80 \pm 0.08 \mathrm{ppm}$.
The XRD pattern obtained from the pure BNNT indicates the presence of a single and dominant h-BN phase (Figure $4 \mathrm{~d}$ ). Peaks were observed at $2 \theta$ angles of $26.8^{\circ}$ and $41.8^{\circ}$ belonging to hexagonal $\mathrm{BN}$. There are not any crystalline phase peaks originating from $\mathrm{CaO}, \mathrm{SiO}_{2}, \mathrm{Al}_{2} \mathrm{O}_{3}, \mathrm{MgO}, \mathrm{SrO}$ or $\mathrm{Na}_{2} \mathrm{O}$ in colemanite and the $\mathrm{Fe}_{2} \mathrm{O}_{3}$ catalyst.

\section{UV-vis, FTIR and Raman analysis of BNNTs}

The BNNTs were analyzed with UV-vis (Figure 4a), FTIR (Figure 4c) and Raman (Figure 4b) spectroscopic techniques. In the UV-vis spectrum of BNNT, a band-gap transition peak at $200 \mathrm{~nm}$ was observed. In addition, an absorption peak in the form of a shoulder which is caused by Van Hove singularities was detected at $273 \mathrm{~nm}$ [30]. The BNNTs give a sharp peak at $1368 \mathrm{~cm}^{-1}$ on the Raman spectrum. This peak shows the $E_{2 \mathrm{~g}}$ in-plane model of h-BN structure and it is due to the bond vibration between $\mathrm{B}$ and $\mathrm{N}$, which is located on the same plane $[3,21]$. E $2 \mathrm{~g}$ vibration peaks were also observed at $1354 \mathrm{~cm}^{-1}$ $[3,22], 1360 \mathrm{~cm}^{-1}$ [21] and $1366 \mathrm{~cm}^{-1}$ [25]. The peak observed at $522 \mathrm{~cm}^{-1}$ originates from the $\mathrm{CaF}_{2}$ slide on the spectrum. Under the same conditions, a vibration peak at $1354 \mathrm{~cm}^{-1}$ was not detected on the Raman spectrum of colemanite. The pure BNNTs were also analyzed by FTIR and it was consistent with the reported FTIR spectrum of BNNTs in the literature [20]. The B-N-B in-plane bonding vibration peak at $1327 \mathrm{~cm}^{-1}$ and the secondary absorption peak at $758 \mathrm{~cm}^{-1}$ were observed. The FTIR spectrum of colemanite has a sharp peak at $3600 \mathrm{~cm}^{-1}$, a broad hydroxyl peak at $3200 \mathrm{~cm}^{-1}$ due to humidity, and other peaks at $1356 \mathrm{~cm}^{-1}, 1305 \mathrm{~cm}^{-1}$ and $886 \mathrm{~cm}^{-1}$.

\section{Conclusions}

In this study, BNNTs were synthesized from unprocessed colemanite for the first time by using $\mathrm{Fe}_{2} \mathrm{O}_{3}$ as a catalyst under a $\mathrm{NH}_{3}$ atmosphere at $1280{ }^{\circ} \mathrm{C}$ and the $\mathrm{CDV}$ technique. The findings suggest that for high-yield synthesis of BNNTs the colemanite/catalyst ratio should be $12 / 1$ (w/w). Impurities such as $\mathrm{Ca}$ and $\mathrm{Fe}$ in the obtained crude product were removed by two hours of washing with a $4 \mathrm{M} \mathrm{HCl}$ solution at $90{ }^{\circ} \mathrm{C}$ to obtain pure BNNTs. The results of the ICP-MS and the XRD analysis showed that the final obtained BNNTs with an impurity of only

Table 1: ICP-MS elemental analysis of colemanite, crude and purified BNNTs.

\begin{tabular}{|c|c|c|c|c|c|c|c|}
\hline & $\begin{array}{l}{ }^{11} \mathrm{~B} \\
\mathrm{ppm}\end{array}$ & $\begin{array}{l}{ }^{23} \mathrm{Na} \\
\mathrm{ppm}\end{array}$ & $\begin{array}{l}{ }^{24} \mathrm{Mg} \\
\mathrm{ppm}\end{array}$ & $\begin{array}{l}{ }^{27} \mathrm{Al} \\
\mathrm{ppm}\end{array}$ & $\begin{array}{l}{ }^{48} \mathrm{Ca} \\
\mathrm{ppm}\end{array}$ & $\begin{array}{l}{ }^{56} \mathrm{Fe} \\
\mathrm{ppm}\end{array}$ & $\begin{array}{l}{ }^{88} \mathrm{Sr} \\
\mathrm{ppm}\end{array}$ \\
\hline Control & $2.56 \pm 0.18$ & - & - & - & $0.74 \pm 0.02$ & - & - \\
\hline Colemanite & $129.30 \pm 1.70$ & $0.22 \pm 0.02$ & $9.10 \pm 0.10$ & $0.34 \pm 0.02$ & $207.60 \pm 4.20$ & $0.24 \pm 0.02$ & $5.62 \pm 0.08$ \\
\hline Crude Product & $34.88 \pm 0.20$ & $0.10 \pm 0.02$ & $10.20 \pm 0.06$ & $0.68 \pm 0.02$ & $214.5 \pm 8.34$ & $40.04 \pm 1.66$ & $5.88 \pm 0.02$ \\
\hline Pure BNNT & - & - & $0.14 \pm 0.02$ & $0.16 \pm 0.02$ & $5.80 \pm 0.08$ & $0.72 \pm 0.02$ & - \\
\hline
\end{tabular}



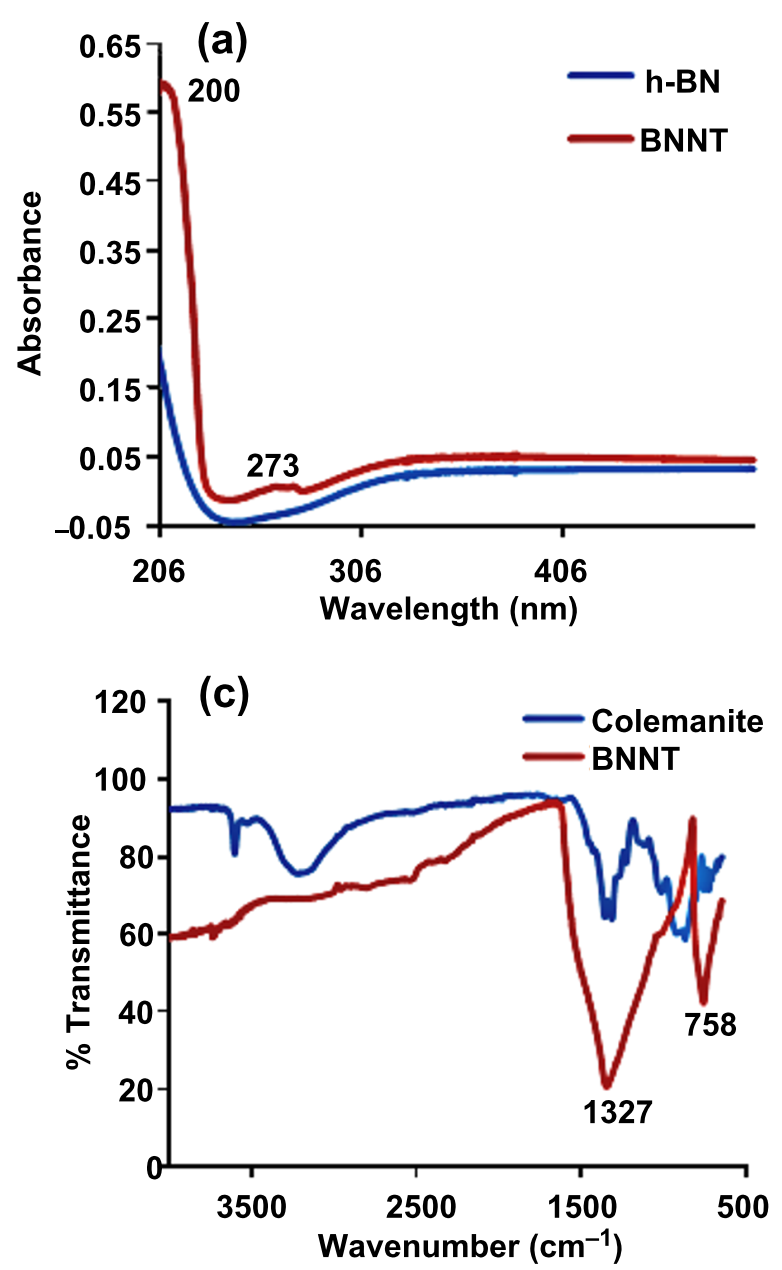
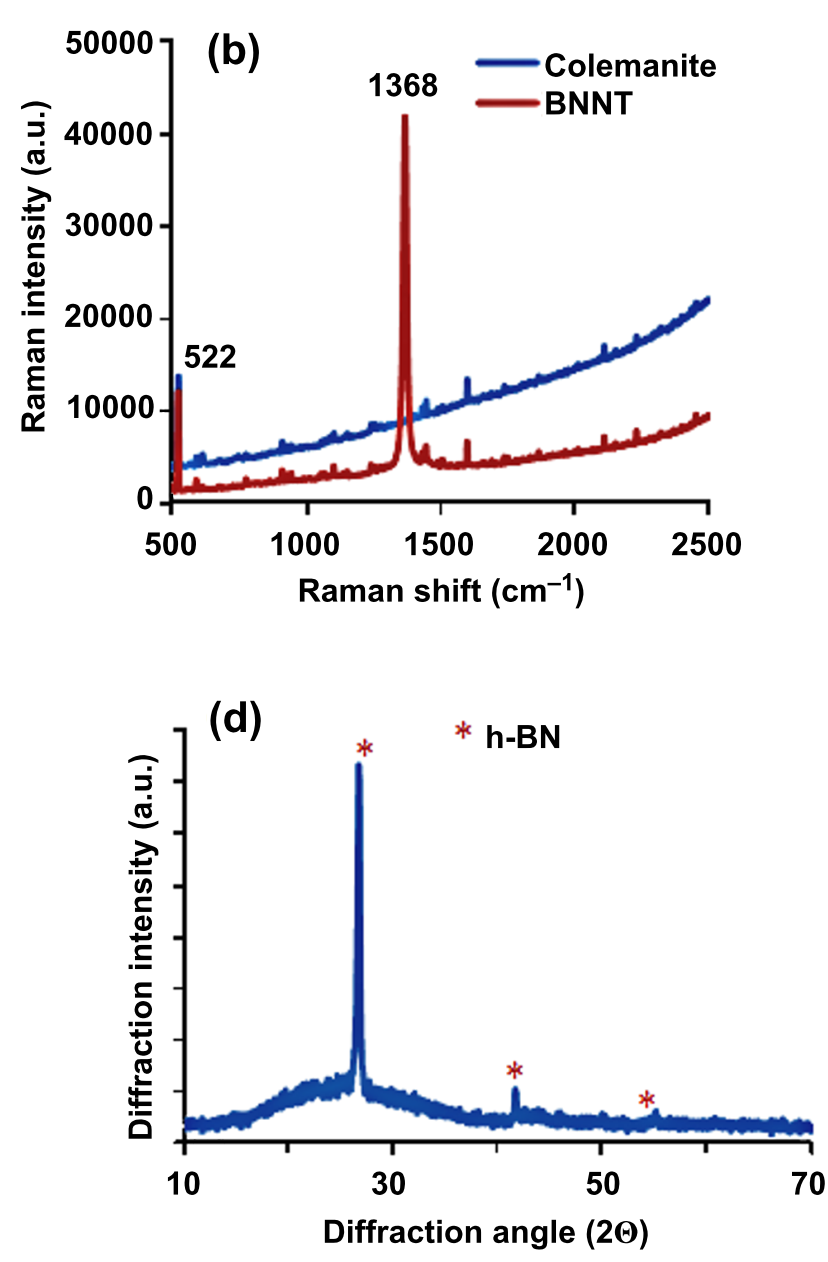

Figure 4: Spectroscopic characterizations of BNNTs: (a) UV spectra of h-BN and BNNTs, (b) Raman spectra of colemanite and BNNTs, (c) FTIR spectra of colemanite and BNNTs, (d) XRD pattern of BNNT.

$5.8 \mathrm{ppm} \mathrm{Ca}$. It was found that the formation of BNNTs synthesis was based on the radical base growth mechanism, which includes the conversion of $\mathrm{Fe}_{2} \mathrm{O}_{3}$ into metallic iron, the formation of an initial complex between metallic iron and $\mathrm{BN}$, and the growth of BN core into BNNTs on the surface of the metallic iron when the surface was super saturated with B and $\mathrm{N}$ atoms. The length of the BNNTs increases as long as the B and N atoms are present in the reaction vessel and stops growing when all boron in colemanite is consumed. The TEM images show that BNNTs formed from colemanite are multi-walled, randomly oriented, have an outer diameter of 10-30 nm and a wall thickness of $5 \mathrm{~nm}$. In conclusion, large scale and pure BNNTs can be obtained by using this novel and simple synthesis method. In addition, the synthesized BNNTs can be purified with a simple acid solution treatment. The obtained BNNTs may be used in many applications including the retention of specific ions, hydrogen storage, and the improvement of the mechanical as well as the chemical durability of polymer composites.

\section{Experimental}

\section{Material and methods}

Colemanite $\left(\mathrm{Ca}_{2} \mathrm{~B}_{6} \mathrm{O}_{11} \cdot 5 \mathrm{H}_{2} \mathrm{O}\right)$ was a gift from Eti Mine Works General Management (Turkey). Iron (III) oxide, iron (II, III) oxide, aluminum oxide, zinc oxide, hydrochloric acid, and nitric acid were provided from Sigma. Highly pure $\mathrm{NH}_{3}$ gas (99.98\%) was provided from Schick $\mathrm{GmbH} \& \mathrm{Co}$. KG. All solutions were prepared with deionized (DI) water.

\section{BNNT synthesis}

$2 \mathrm{~g}$ of colemanite and $0.166 \mathrm{~g} \mathrm{Fe}_{2} \mathrm{O}_{3}$ were suspended in $2 \mathrm{~mL}$ DI water and vortexed until full dispersion. The homogeneous 
mixture was transferred into an alumina boat. The water was evaporated with pre-heating at $180{ }^{\circ} \mathrm{C}$ for $15 \mathrm{~min}$, and the alumina boat was placed into the center of the tubular furnace (Protherm, Furnaces PTF 14/50/450). The BNNT synthesis was performed under $\mathrm{NH}_{3}$ atmosphere. The furnace temperature was set to a heating rate of $8{ }^{\circ} \mathrm{C} / \mathrm{min}$ until $1280{ }^{\circ} \mathrm{C}$ and then heated at this temperature for 3 hours. The furnace was left for cooling down to $520^{\circ} \mathrm{C}$, and the reaction boat was removed from the furnace. The BNNTs were collected from the top of alumina boat and kept in a dry environment at room temperature.

\section{Purification}

The BNNTs were added into $50 \mathrm{~mL} 4 \mathrm{M} \mathrm{HCl}$ for 4 hours at $90{ }^{\circ} \mathrm{C}$ by stirring and then precipitated by centrifugation (14000 rpm, $30 \mathrm{~min}$ ). The obtained product was stirred in $30 \mathrm{~mL}$ of $1 \mathrm{M} \mathrm{HNO}_{3}$ for 6 hours at $30^{\circ} \mathrm{C}$ and then precipitated by centrifugation at $14000 \mathrm{rpm}$ for $30 \mathrm{~min}$. After the centrifugation, the remaining solid was washed with DI water until all acid was removed. The pure BNNTs were dried at $60{ }^{\circ} \mathrm{C}$ overnight.

\section{X-Ray powder diffractometer}

X-ray powder diffraction (XRD Shimadzu XRD-6000, ICDD PDF 4 software) analyses were carried out with Drive Axis Theta-2Theta. The scan range was 2.000-69.980 in continuous scan with a scan rate of $2.0000 \mathrm{deg} / \mathrm{min}$. The sampling pitch was set to $0.0200 \mathrm{deg}$, the preset time was $0.60 \mathrm{~s}$.

\section{Inductively coupled plasma-mass spectrometer}

The analyses were performed by using an X Series 2 Inductively Coupled Plasma-Mass Spectrometer (ICP-MS) (Thermo Scientific) and a CETAC asx-520 auto sampler. Plasma power $(1350 \mathrm{~W})$, plasma gas (Ar), Nebulizer gas flow rate (0.95 L/min), uptake time (35 $\mathrm{min}$ ) and wash time (35 $\mathrm{min})$ were optimized in an ICP-MS system. VHG Labs Z frequency 1007-100 multi-element standard solutions of $\mathrm{Al}, \mathrm{B}, \mathrm{Cu}, \mathrm{Ag}$, As, Cd, Fe, Ni, Sr, Zn, Ca, P, Hg $(1000 \mu \mathrm{g} / \mathrm{mL})$ were used as stock solution. $0.1 \mu \mathrm{g} / \mathrm{mL}, 1 \mu \mathrm{g} / \mathrm{mL}, 10 \mu \mathrm{g} / \mathrm{mL}, 100 \mu \mathrm{g} / \mathrm{mL}$ of standard solution in $5 \% \mathrm{HNO}_{3}$ from the stock solution were prepared. Each sample was measured for three times and calibration curves were created for each metal. A $10 \mathrm{mg}$ sample was boiled in $5 \mathrm{~mL} \mathrm{HNO}_{3}: \mathrm{HCl}(2: 1 \mathrm{v} / \mathrm{v})$ for $15 \mathrm{~min}$ and sonicated for $10 \mathrm{~min}$, and the final volume was completed to $20 \mathrm{~mL}$ with DI water. After the sample was dissolved, it was filtered with a $0.2 \mu \mathrm{m}$ syringe driven filter. The prepared sample was analyzed by ICP-MS.

\section{Scanning electron microscopy}

The sample was placed on a carbon disc and coated with a few $\mathrm{nm}$ thick gold-layers by using a Baltec SDC 005 sputter-coater.
Scanning electron microscopy (SEM) images were obtained by using a Carl Zeis Evo-40 instrument under high vacuum with an accelerating voltage of $10 \mathrm{kV}$.

\section{Raman spectroscopy}

All Raman Spectroscopic measurements were performed by a completely automated Renishaw InVia Reflex Raman Microscopy system (Renishaw Plc., New Mills, Wotton-underEdge, UK) equipped with a $514 \mathrm{~nm}$ Ar lasers. The laser power was set at $30 \mathrm{~mW}$, and the exposure time was 10 s. A $50 \times$ objective was used. The wavelength of the instrument was automatically calibrated by using an internal silicon wafer, and the spectrum was centered at $520 \mathrm{~cm}^{-1}$. All spectra were acquired with a $514 \mathrm{~nm}$ laser.

\section{Transmission electron microscopy}

Transmission electron microscopy (TEM) measurements were performed with JEOL-2100. High Transmission electron microscopy (HRTEM) operating at $120 \mathrm{kV}$ (LaB6 filament) equipped with an Oxford Instruments 6498 EDS system.

\section{Acknowledgements}

We acknowledge the support from the Scientific and Technological Research Council of Turkey (TUBITAK) (Project No: 112M480) and from the Yeditepe University.

\section{References}

1. Acarkan, N.; Bulut, G.; Kangal, O.; Önal, G. Miner. Eng. 2005, 18, 739-741. doi:10.1016/j.mineng.2004.12.005

2. Ata, O. N.; Çolak, S.; Çopur, M.; Çelik, C. Ind. Eng. Chem. Res. 2000, 39, 488-493. doi:10.1021/ie990314z

3. Wang, J.; Gu, Y.; Zang, L.; Zhao, G.; Zang, Z. J. Nanomater. 2010, No. 540456. doi:10.1155/2010/540456

4. Deepak, F. L.; Vinod, C. P.; Mukhopadhyay, K.; Govindaraj, A.; Rao, C. N. R. Chem. Phys. Lett. 2002, 353, 345-352. doi:10.1016/S0009-2614(02)00007-6

5. Golberg, D.; Bando, Y.; Tang, C.; Zhi, C. Adv. Mater. 2007, 19, 2413-2432. doi:10.1002/adma.200700179

6. Okan, B. S.; Kocabaş, Z. O.; Ergün, A. N.; Baysal, M.; Letofsy-Papst, I.; Yürüm, Y. Ind. Eng. Chem. Res. 2012, 51, 11341-11347. doi:10.1021/ie301605z

7. Lee, C. H.; Drelich, J.; Yap, Y. K. Langmuir 2009, 25, 4853-4860. doi:10.1021/la900511z

8. Hilder, T. A.; Gordon, D.; Chung, S.-H. Small 2009, 5, 2870-2875. doi:10.1002/smll.200901229

9. Velayudham, S.; Lee, C. H.; Xie, M.; Blair, D.; Bauman, N.; Yap, Y. K.; Green, S. A.; Liu, H. ACS Appl. Mater. Interfaces 2010, 2, 104-110. doi:10.1021/am900613j

10. Wang, J.; Lee, C. H.; Bando, Y.; Golberg, D.; Yap, Y. K. Multiwalled Boron Nitride Nanotubes: Growth, Properties and Applications.. In B-C-N Nanotubes and Related Nanostructures; Yap, Y. K., Ed.; Lecture Notes in Nanoscale Science and Technology, Vol. 6; Springer: Berlin, 2009; pp 23-44.

11. Zhi, C.; Bando, Y.; Tang, C.; Golberg, D. J. Am. Chem. Soc. 2005, 127, 17144-17145. doi:10.1021/ja055989+ 
12. Li, L. H.; Chen, Y.; Glushenkov, A. M. J. Mater. Chem. 2010, 20, 9679-9683. doi:10.1039/c0jm01414a

13. Horváth, L.; Magrez, A.; Golberg, D.; Zhi, C.; Bando, Y.; Smajda, R.; Horváth, E.; Forró, L.; Schwaller, B. ACS Nano 2011, 5, 3800-3810. doi:10.1021/nn200139h

14. Chopra, N. G.; Luyken, R. J.; Cherrey, K.; Crespi, V. H.; Cohen, M. L.; Louie, S. G.; Zettl, A. Science 1995, 269, 966-967. doi:10.1126/science.269.5226.966

15. Golberg, D.; Bando, Y.; Huang, Y.; Terao, T.; Mitome, M.; Tang, C.; Zhi, C. ACS Nano 2010, 4, 2979-2993. doi:10.1021/nn1006495

16. Han, W. Q.; Bando, Y.; Kurashima, K.; Sato, T. Appl. Phys. Lett. 1998, 73, 3085-3088. doi:10.1063/1.122680

17. Shelimov, K. B.; Moskovits, M. Chem. Mater. 2000, 12, 250-254. doi:10.1021/cm9905996

18. Han, W.-Q.; Cumings, J.; Huang, X.; Bradley, K.; Zettl, A. Chem. Phys. Lett. 2001, 346, 368-372. doi:10.1016/S0009-2614(01)00993-9

19. Yu, J.; Chen, Y.; Wuhrer, R.; Liu, Z.; Ringer, S. P. Chem. Mater. 2005, 17, 5172-5176. doi:10.1021/cm050966f

20. Zhong, B.; Huang, X.; Wen, G.; Yu, H.; Zhang, X.; Zhang, T.; Bai, H. Nanoscale Res. Lett. 2011, 6, No. 36 . doi:10.1007/s11671-010-9794-8

21. Singhal, S. K.; Srivastava, A. K.; Singh, B. P.; Gupta, A. K. Indian J. Eng. Mater. Sci. 2008, 15, 419-424.

22. Wang, J.; Kayastha, V. K.; Yap, Y. K.; Fan, Z.; Lu, J. G.; Pan, Z.; Ivanov, I. N.; Puretzky, A. A.; Geohegan, D. B. Nano Lett. 2005, 5, 2528-2532. doi:10.1021/n1051859n

23. Lee, C. H.; Wang, J.; Kayatsha, V. K.; Huang, J. Y.; Yap, Y. K. Nanotechnology 2008, 19, 455605. doi:10.1088/0957-4484/19/45/455605

24. Lee, C. H.; Xie, M.; Kayastha, V.; Wang, J.; Yap, Y. K. Chem. Mater. 2010, 22, 1782. doi: $10.1021 / \mathrm{cm} 903287 \mathrm{u}$

25. Pakdel, A.; Zhi, C.; Bando, Y.; Nakayama, N.; Golberg, D. Nanotechnology 2012, 23, 215601. doi:10.1088/0957-4484/23/21/215601

26. Chadderton, L. T.; Chen, Y. J. Cryst. Growth 2002, 240, 164-169. doi:10.1016/S0022-0248(02)00855-2

27. Tang, C.; Bando, Y.; Sato, T. Chem. Phys. Lett. 2002, 362, 185-189. doi:10.1016/S0009-2614(02)00973-9

28. Zhi, C.; Bando, Y.; Tang, C.; Xie, R.; Sekiguchi, T.; Golberg, D. J. Am. Chem. Soc. 2005, 127, 15996-15997. doi:10.1021/ja053917c

29. Su, C.-Y.; Chu, W.-Y.; Juang, Z.-Y.; Chen, K.-F.; Cheng, B.-M.; Chen, F.-R.; Leou, K.-C.; Tsai, C.-S. J. Phys. Chem. C 2009, 113, 14732-14738. doi:10.1021/jp904583p

30. Ishigami, M.; Sau, J. D.; Aloni, S.; Cohen, M. L.; Zettl, A. Phys. Rev. Lett. 2005, 94, 1-4. doi:10.1103/PhysRevLett.94.056804

\section{License and Terms}

This is an Open Access article under the terms of the Creative Commons Attribution License

(http://creativecommons.org/licenses/by/2.0), which permits unrestricted use, distribution, and reproduction in any medium, provided the original work is properly cited.

The license is subject to the Beilstein Journal of Nanotechnology terms and conditions:

(http://www.beilstein-journals.org/bjnano)

The definitive version of this article is the electronic one which can be found at:

doi:10.3762/bjnano.4.95 